\title{
CARACTERIZAÇÃO GENÉTICA DE POPULAÇÕES DE EGERIA NAJAS PRESENTES NO RESERVATÓRIO DE JUPIÁ E RIOS AFLUENTES ${ }^{1}$
}

\author{
EDSON S. MORI ${ }^{2}$, CANTÍDIO F. GOUVEA ${ }^{3}$, SUZI M. M. LEITE ${ }^{4}$, CELSO L. MARINO ${ }^{5}$, \\ DAGOBERTO MARTINS ${ }^{2}$ E EDIVALDO D. VELINI ${ }^{2}$
}

\section{RESUMO}

A Egeria najas é uma espécie aquática submersa nativa da bacia hidrográfica do rio Paraná. Com o represamento das águas do rio para geração de energia elétrica a espécie tem mudado seu comportamento de colonização dos leitos dos rios e ocorrido em grandes maciços dentro da represa de Jupiá e rios afluentes. Essa planta tem causado problemas por obstruir a passagem de água para as turbinas de geração de energia elétrica. Coletas de material vegetativo foram realizadas na represa e afluentes do rio Paraná para análise da variabilidade isoenzimática e de DNA. A análise isoenzimática mostrou haver somente quatro classes de diferentes biotipos. No entanto, utilizando-se os procedimentos de RAPD, observou-se que a espécie possui grande variabilidade genética. $\mathrm{O}$ represamento das águas também está permitindo o acumulo de variabilidade no local e promovendo um aumento de variabilidade por meio de possíveis cruzamentos entre genótipos diferentes. Os resultados também possibilitaram inferir sobre as possíveis rotas de migração de material genético para colonização da represa e rios afluentes.

Palavras chaves: Planta daninha, isoenzimas, planta aquática.

\section{ABSTRACT \\ Genetic characterization of Egeria najas presented in the Jupia Lake and its tributaries}

The submerged aquatic species Egeria najas occurs naturally in the Parana River Basin Brazil. Several lakes have been constructed by CESP - Centrais Elétricas do Estado de São Paulo S.A. in the river basin, changing the ecology of the region. The species have altered their establishment strategy, and now grows in large, dense populations on the floor of Jupia Lake and its tributaries. This has had a negative impact on electricity generation as the branches of these species routinely block the hydroelectric turbines. We used genetic markers to study the pattern of genetic diversity in the species using plant material collected along Jupia Lake and the Paraná River Tributaries. Isoenzymes have shown four different biotypes, however, the RAPD technique has demonstrated greater genetic variability among individuals. The creation of Jupia Lake has resulted in an increase in genetic variability probably by migration of large amount of seeds and vegetative branches. These materials are increasing the genetic diversity in populations in the lake by favoring outcrossing among different genotypes. Results also present a possible understanding of Egeria najas genotype migrations in populations in the Jupia Lake and its tributaries.

Key words: Weed, isoenzymes, aquatic weeds

\footnotetext{
${ }^{1}$ Recebido para publicação em 28/11/98 e na forma revisada em 07/04/99.

${ }^{2}$ Professor Dr., Departamento de Agricultura e Melhoramento Vegetal, FCA/UNESP. Botucatu/SP, C.P. 237, CEP: 18603-970.

${ }^{3}$ Engenheiro Florestal, Departamento de Agricultura e Melhoramento Vegetal, FCA/UNESP, Botucatu/SP.

${ }_{5}^{4}$ Engenheira Florestal Ms., Departamento de Genética, IB/UNESP, Botucatu/SP.

${ }^{5}$ Professor Dr., Departamento de Genética, IB/UNESP, Botucatu/SP.
} 


\section{INTRODUÇÃO}

O potencial hidroelétrico brasileiro é um dos maiores do mundo. Das inúmeras bacias hidrográficas existentes no país, a do Rio Paraná destaca-se como uma das mais importantes, pela sua posição e volume hidráulico.

Com o aumento do consumo de energia elétrica, especialmente na região sudeste foram implantadas várias usinas hidrelétricas. Tais procedimentos causaram consideráveis mudanças ambientais, em função da criação de extensos lagos formados pelo represamento de água, alterando as condições microclimáticas e das espécies locais. Dentre as espécies com comportamento modificado está a planta aquática submersa Egeria najas que se beneficiou da nova situação e se multiplicou desordenadamente em lagos artificiais, causando sérios problemas econômicos $\mathrm{e}$ ecológicos.

A espécie E. najas, nativa da bacia hidrográfica do rio Paraná, esteve presente desde os primeiros anos após a construção do reservatório de Jupiá, mas tornou-se problema somente após a construção da usina hidroelétrica de Três Irmãos, no rio Tietê, um de seus mais importantes afluentes. Com o fechamento da barragem para formação do lago, interrompeu-se o fluxo de água do rio por um extenso período, permitindo que a espécie se estabelecesse ocupando boa parte do fundo do rio.

A E. najas é uma planta dióica e morfologicamente muito parecida com as outras Hydrocaritaceae, como por exemplo a Elodea densa, Egeria densa e a Hydrilla verticilatta, esta última com grande presença nos reservatórios dos Estados Unidos (Kissmann, 1991).

A caracterização de populações de plantas é de extrema importância para estabelecer controles apropriados, minimizar custos e garantir repetitividade dos resultados em campo. Técnicas de eletroforese tem sido utilizadas para se conhecer as relações genéticas entre populações e espécies de plantas aquáticas e de outros organismos (Wain et al., 1985). As isoenzimas permitem estudar geneticamente diferentes populações e realizar comparações entre elas (Hedrick, 1971; Nei, 1972; Rogers, 1972; Nei, 1978). A técnica mostra-se de grande valor quando combinada com outros tipos de dados morfológicos e bioquímicos para identificar e marcar grupos sistemáticos distintos. Em plantas aquáticas, poucas variações isoenzimáticas intraespecíficas tem sido observadas, sendo que as maiores variações tem ocorrido entre espécies (Wain et al, 1985).

Raros são os trabalhos sobre caracterização molecular de plantas aquáticas. Verkleij et al (1983), um dos poucos pesquisadores na área, realizaram estudos sobre a variabilidade genética de 28 populações de Hydrilla verticilata (L. F.) Royle coletadas no Paquistão, Índia, Malásia, Indonésia, Nova Zelândia, Estados Unidos, Panamá e Polônia. Morfologicamente encontraram diferenças nos tamanhos e inserções das folhas no caule. Os autores estudaram 18 sistemas isoenzimáticos não encontrando variabilidade genética em três deles: Aconitase, Fumarase e Glucose desidrogenase. Observaram grande variabilidade entre populações, porém nos reservatórios dos Estados Unidos, não ocorreram diferenças nos padrões morfológicos e isoenzimáticos, indicando serem oriundas da colonização vegetativa de um único clone de Hydrilla.

Padrões de eletroforese de proteínas totais, através da desnaturação das mesmas com SDS (Dodecil Sulfato de Sódio), de biotípos de Hydrilla verticilata foram obtidas por Ryan (1988), que observou bandas com diferentes pesos moleculares entre os biotípos utilizados. Observou também diferentes padrões de proteínas entre eles.

Less (1991) estudou 12 populações de Ceratophyllum demersum e de Ceratophyllum echinatum, em Wisconsin, por meio de isoenzimas para quantificar a variabilidade genética. $\mathrm{O}$ autor utilizou 10 sistemas isoenzimáticos que foram: ALD, AAT, GDH, PGI, TPI, IDH, MDH, 6PGDH, PGM e SKDH. Os resultados mostraram que as populações apresentavam baixos níveis de recombinação sexual, baixos níveis de variação e endogamia. O monoicismo em Ceratophyllum pode estar relacionado a fatores evolucionário 
históricos, entretanto a propagação vegetativa têm uma grande influência na estrutura genética das populações.

A espécie do presente estudo possui poucas informações sobre morfologia e biologia, e estudos moleculares podem possibilitar melhor entendimento sobre o seu comportamento. Portanto, o objetivo desse trabalho foi estudar a variabilidade genética das populações de Egeria najas na represa de Jupiá e rios afluentes, por meio de isoenzimas e RAPD.

\section{MATERIAL E MÉTODOS}

\section{Coleta de plantas}

Amostraram-se treze locais de coleta, distribuídos aleatóriamente na represa de Jupiá, no rio Tietê, no canal de Pereira Barretos e no rio São
José dos Dourados, onde as plantas estavam presentes. Os locais de coletas estão plotados no mapa da Figura 1.

Para cada ponto de coleta, procurou-se colher 7 sub-amostas distanciadas a $200 \mathrm{~m}$ umas das outras, perfazendo um total de 46 plantas (subamostras). Os pontos foram distribuídos aleatoriamente em relação a área afetada e recebendo numeração prévia.

Os locais de coleta e número de pontos de coleta são apresentados na Tabela 1. As plantas foram conduzidas ao laboratório do Departamento de Agricultura e Melhoramento Vegetal da Faculdade de Ciências Agronômicas da UNESP Campus de Botucatu, onde foram colocadas em provetas previamente identificadas, em presença de solução nutritiva, para garantir melhor crescimento e condições ideais para extração de DNA e de enzimas para eletroforese.

TABELA 1. Locais de coleta de material vegetativo e número de amostas coletadas no reservatório de Jupiá, no rio Tietê, no canal de Pereira Barretos e no rio São José dos Dourados.

\begin{tabular}{|c|c|c|}
\hline Local de Coleta & $\mathrm{n}^{\mathrm{o}}$ do ponto de coleta & $\begin{array}{l}\mathrm{n}^{\mathrm{o}} \text { de sub-amostra por } \\
\text { ponto de coleta }\end{array}$ \\
\hline \multirow[t]{3}{*}{ - rioTietê } & 01 & 2 \\
\hline & 02 & 1 \\
\hline & 04 & 1 \\
\hline \multirow[t]{4}{*}{ - reservatorio de Jupiá } & 05 & 5 \\
\hline & 06 & 7 \\
\hline & 07 & 5 \\
\hline & 08 & 2 \\
\hline - canal de Per. Barretos & 09 & 7 \\
\hline \multirow[t]{4}{*}{ - rio S.José dos Dourados } & 10 & 1 \\
\hline & 11 & 7 \\
\hline & 12 & 7 \\
\hline & 13 & 1 \\
\hline \multicolumn{2}{|c|}{ TOTAL DE INDIVÍDUOS COLETADOS } & 46 plantas \\
\hline
\end{tabular}

\section{Isoenzimas}

A extração das enzimas foi feita segundo os procedimentos de Verkleij (1983). Utilizou-se uma grama de tecido fresco de limbos foliares de ramos cultivados em solução nutritiva, com luz e temperatura controladas.

Foram utilizados géis de penetrose de milho a $12 \%$ de concentração, adaptando metodologia apresentada por Alfenas et al (1991). 


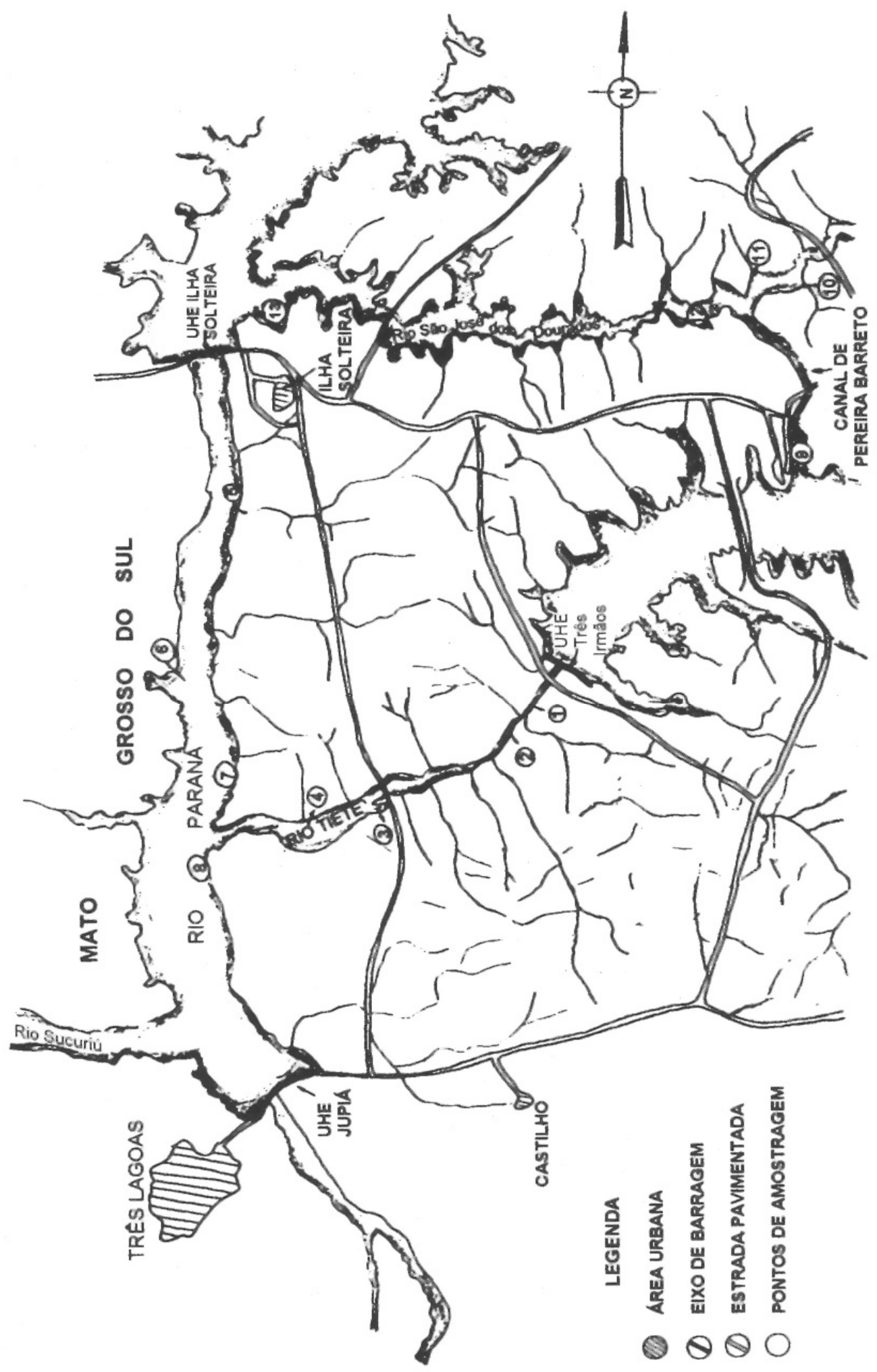

FIGURA-1 - Locais de Coleta 
Testaram-se três soluções gel / eletrodo descritas por Cheliak e Pitel (1984), e Ballve et al (1991).

Dezessete foram os sistemas enzimáticos testados (Catalase, CAT E. C. 1.11.1.6; Glutamato desidrogenase, GDH - E.C.1.4.1.3; 6Fosfogluconato desidrogenase, 6PGDH - E.C. 1.1.1.44; Glucose-6-fosfato desidrogenase, G6PDH - E.C. 1.1.1.49; Peroxidase, PO - E. C. 1.11.1.7; Glutamato-piruvato transaminase, GPTE. C. 2.6.2.2; Glutamato-piruvato transaminase, GPT- E. C. 2.6.2.2; Aspartato aminotransferase, AAT - E. C. 2. 6. 1. 1; Isocitrato desidrogenase, IDH - E. C. 1.1.1.42; Leucina aminopeptidase, LAP - E. C. 3.4.11.1; Malato desidrogenase, $\mathrm{MDH}$ - E. C. 1.1.1.37; Polifenoloxidase, PPO - E. C. 1.14.18.1; Xiquimato desidrogenase, SKDH - E. C. 1.1.1.25; Fosfoglucose isomerase, PGI - E. C. 5.3.1.9; Fosfoglucomutase, PGM - E. C. 2.7.5.1; Fosfatase ácida, ACP - E. C. 3.1.3.2; $\alpha$-Esterase, $\alpha$ - EST E. C. 3.1.1.1 e $\beta$ - Esterase, $\beta$ - EST E. C. 3.1.1.1.

\section{RAPD}

Com base nos resultados de isoenzimas foram escolhidas as plantas que foram submetidas aos procedimentos de RAPD. A técnica de RAPD empregada foi baseada no protocolo de Williams et al. (1990) e modificada por Grattapaglia \& Sederoff (1994).

Os dados foram analisados por presença e ausência de bandas utilizando-se o software POPGENE version 1.20 de Yeh et al. (1997). Matrizes de distância genética foram obtidas utilizando-se o método de análise de grupamento UPGMA (Unweighted Pair Group Method with Arithmetic Averages de Rohlf, 1992). Dendrogramas foram utilizados para observar a distância genética entre as plantas analisadas.

\section{RESULTADOS E DISCUSSÃO}

\section{Coleta de Material}

Inicialmente intensionou-se realizar treze locais de coletas, no entanto, nem todos os locais possuiam populações de E. najas. Esta foi a razão de se coletarem diferentes números de subamostras nos diferentes pontos de coleta de material. Originalmente, além destes locais estudados planejou-se coletar também no rio Sucuruí. A expedição de coleta percorreu grande parte do rio e de seus afluentes durante um dia todo de barco, não encontrando nenhuma colônia da espécie. Observaram-se apenas, raros ramos vegetais flutuando e próximos a represa de Jupiá. Provavelmente, os ramos tenham vindo por meio do refluxo das águas da represa, fato que normalmente ocorre próximo a foz.

Nas margens da represa e rios, com fluxo lento das águas, ou com águas praticamente paradas, as colônias de Egeria najas aparecem, na grande maioria das vezes, em grandes maciços vegetais. No entanto, em locais de correntezas d'água aparecem com menor frequência. No segmento do rio Tietê, abaixo da represa de Três Irmãos, a colonização da espécie é extremamente intensa, inclusive em locais de grande correnteza de água.

\section{Análises isoenzimáticas}

Dos dezessete sistemas isoenzimáticos testados, foram escolhidas as isoenzimas $\mathrm{MDH}$, IDH, SKDH, ACP e AAT, que apresentaram polimorfismo alélico. Estes sistemas apresentaram os seguintes padrões isoenzimáticos como se observa na Tabela 2.

Nas análises isoenzimáticas de $\mathrm{MDH}$, IDH, SKDH, ACP e AAT foram encontrados somente dois padrões distintos de bandas, que diferenciaram os materiais genéticos. A Tabela 3 apresenta os pontos de coleta e os padrões de bandas isoenzimáticas ( 1 e 2 ) para as E. najas.

Os padrões isoenzimáticos obtidos no presente trabalho separaram os indivíduos em quatro classes distintas. Os padrões de isoenzimas pouco discriminaram diferenças entre eles. Poder-se-ia concluir, então, por meio destes resultados, que pouca variabilidade genética estaria ocorrendo nas populações estudadas. Entretanto, para comprovar estes resultados, utilizou-se também os procedimentos de eletroforese de DNA (a técnica de RAPD). Em certos casos, as isoenzimas são ferramentas limitadas para discriminar diferenças entre indivíduos. 
TABELA 2. Diferentes padrões isoenzimáticos encontrados para os cinco sistemas testados.

\begin{tabular}{lcc}
\hline Sistema isoenzimático & \multicolumn{2}{c}{$\mathrm{N}^{\mathbf{0}}$ de bandas } \\
\cline { 2 - 3 } & Padrão 01 & Padrão 02 \\
\hline MDH & 02 & 03 \\
IDH & 02 & 01 \\
SKDH & 01 & 01 \\
ACP & 02 & 04 \\
AAT & $04^{*}$ & $04^{*}$ \\
\hline
\end{tabular}

Observação: *bandas em posiçoes diferentes.

TABELA 3. Padrões isoenzimáticos de Egeria najas e locais de coleta.

\begin{tabular}{ccccccc}
\hline LOCAL DE COLETA* & \multicolumn{4}{c}{ PADRÃO } \\
& Mdh & Idh & Skd & Acp & Aat \\
\hline 8-1 e 8-2 & 1 & 1 & 1 & 1 & 1 \\
$1-4$ e $1-7$ & 1 & 1 & 1 & 2 & 2 \\
$4-5,7-1$ a 7-4 e 7-7 & 1 & 2 & 1 & 2 & 2 \\
$5-1,5-3$ a 5-7, 6-1 a 6-7, 8-1, 9-1 a 9-7, 10-1, 11-1 a 11- & 2 & 2 & 1 & 2 & 2 \\
$7,12-1$ a 12-7, 2-6 & & & & & \\
\hline
\end{tabular}

*Local-Subamostra ( exemplo: 1-7 significa local 1 e sub-amostra 7 ).

\section{Análises RAPD}

Foram testados 38 "primers" dos quais, a grande maioria apresentou produto de amplificação e outros não apresentaram clareza de resolução para avaliação das bandas. Seis "primers Operon" ( J1, J11, J17, P1, P16 e P17 ) que mostraram boa resolução e polimorfismo foram selecionados para o presente estudo.

A Figura 2 mostra uma foto com alguns "primers" estudados.

\section{Análise Biométrica}

Para análise mais completa da variabilidade das populações de E. najas, utilizaram-se somente os dados de RAPD. A Figura 3 apresenta o dendrograma de distâncias genéticas dos 46 indivíduos avaliados, em conjunto, por 75 diferentes bandas polimórficas de RAPD.
$\mathrm{Na}$ análise de grupamento observou-se que a $E$. najas possui variabilidade genética, mostrando que as populações são formadas por diversos genótipos com pequenas diferenças genéticas entre plantas.

Os indivíduos foram separados por distâncias genéticas inferiores a 0,24 , ou seja, possuem similaridades genéticas superiores a 0,76.

A similaridade também foi grande entre o material colhido no rio São José dos Dourados (superior a 0,90 ).

O dendrograma de distâncias genéticas divide as plantas em dois grupos distintos. Um grupo é composto por plantas colhidas no canal de Pereira Barretos (local 9), no rio São José dos Dourados (locais 10, 11 e 12) e na represa de Jupiá (locais 7 e 8). O local de coleta $\mathrm{n}^{\mathrm{0}} 7$ está acima da entrada do rio Tiête, tendo possibilidade do local ter sido colonizado a partir de populações do Rio São José dos Dourados. O outro grupo no 
dendrograma de distâncias de Nei é formado por plantas coletadas no rio Tiête (locais 1,2 e 4) e na represa de Jupiá (locais 5,6 e outra coleta do local 8). Os locais 5 e 6 estão acima da entrada do rio Tiête na represa de Jupiá e podem ter origens a partir de materiais genéticos oriundos do rio Tiête, que migraram pelo fluxo das águas vindas pelo canal de Pereira Barretos, rio São José dos Dourados, represa de Ilha Solteira e, então, até a represa de Jupiá.

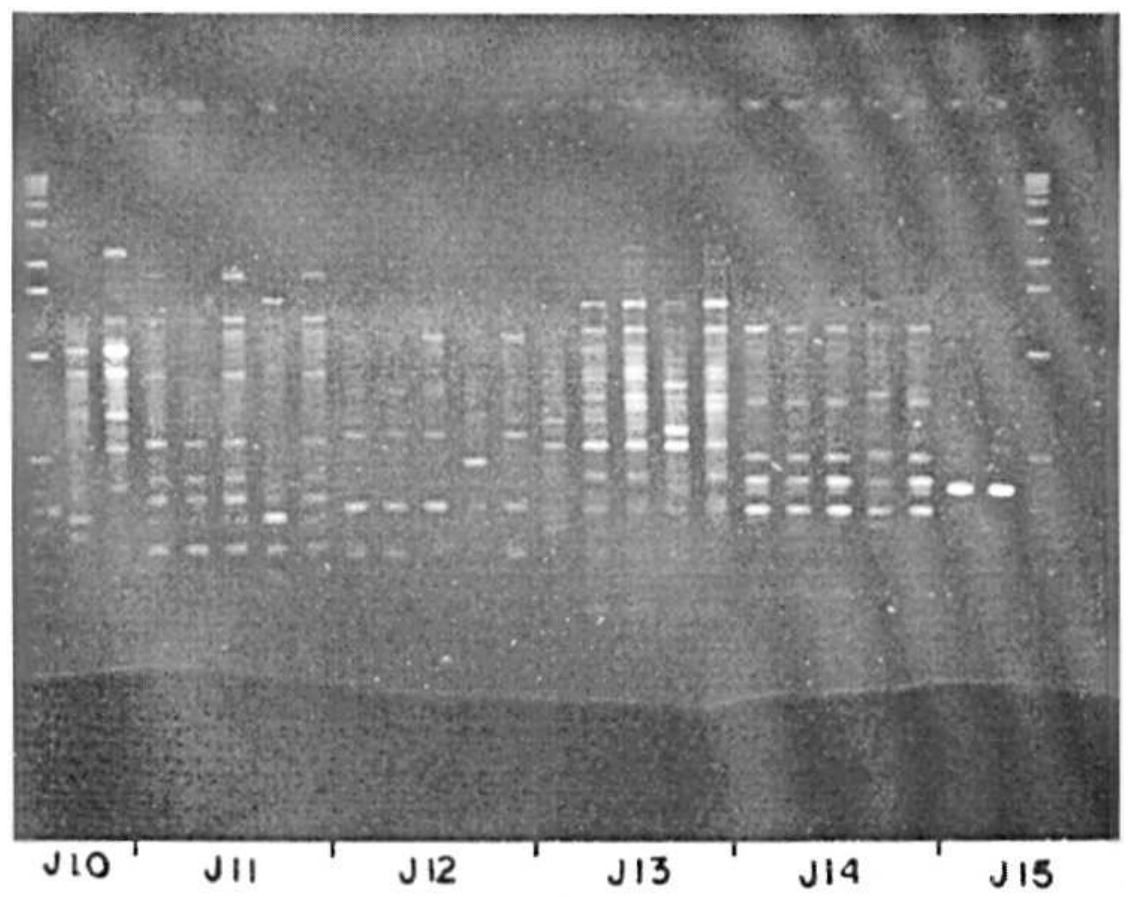

FIGURA 2. Foto com diferentes "primers" testados.

Foram analisadas duas sub-amostras de $E$. najas no local 1 do rio Tietê, que foram retiradas a uma distância aproximada de $800 \mathrm{~m}$ uma da outra e o índice de similaridade mostrou serem materiais do mesmo clone, demonstrando a possibilidade de existência de grandes colônias formadas por via vegetativa.

A variabilidade genética observada nas populações estudadas pode ser originária de propagação sexuada entre indivíduos convivendo nos reservatórios, e/ou oriunda de material vegetativo variável, de diferentes origens dos afluentes da bacia do rio Paraná. Segundo Kissmann (1991) a dispersão de Egeria por sementes é mínima, e por esta razão supõe-se que a maior fonte de variabilidade nos reservatórios são oriundos de material vegetativo migrante a represa.
A maioria dos estudos sobre plantas aquáticas encontrados na literatura referem-se a grandes populações de plantas exóticas, originárias de um ou de poucos genótipos, que se alastraram em determinados ambientes. A variabilidade normalmente é pequena ou nula entre indivíduos, como foi citado por Verkleij et al (1983), com a espécie Hydrilla verticilata em lagos artificiais nos Estados Unidos. No entanto, o reservatório de Jupiá está acumulando plantas de E. najas que é nativa da bacia do rio Paraná. O reservatório está possibilitando o represamento de variabilidade genética que tem migrado ao ambiente, principalmente via propagação vegetativa, carregadas pelo fluxo das águas.

Em condiçoes naturais, dificilmente plantas do sexo masculino e do sexo feminino ocorrem fisicamente próximos. Isto dificulta a 
polinização que é preferencialmente realizada por insetos (Kissmann, 1991). No entanto, com esta nova situação ambiental, de alta densidade populacional, facilitou a propagação sexuada, possibilitando o aumento da variabilidade genética das populações de Egeria najas.
O estudo apresentou resultados básicos, úteis para os procedimentos de controles químico e biológico. A variabilidade genética existente nas populações de Egeria najas deve ser considerada nas metodologias de manejo e controle dessa espécie.

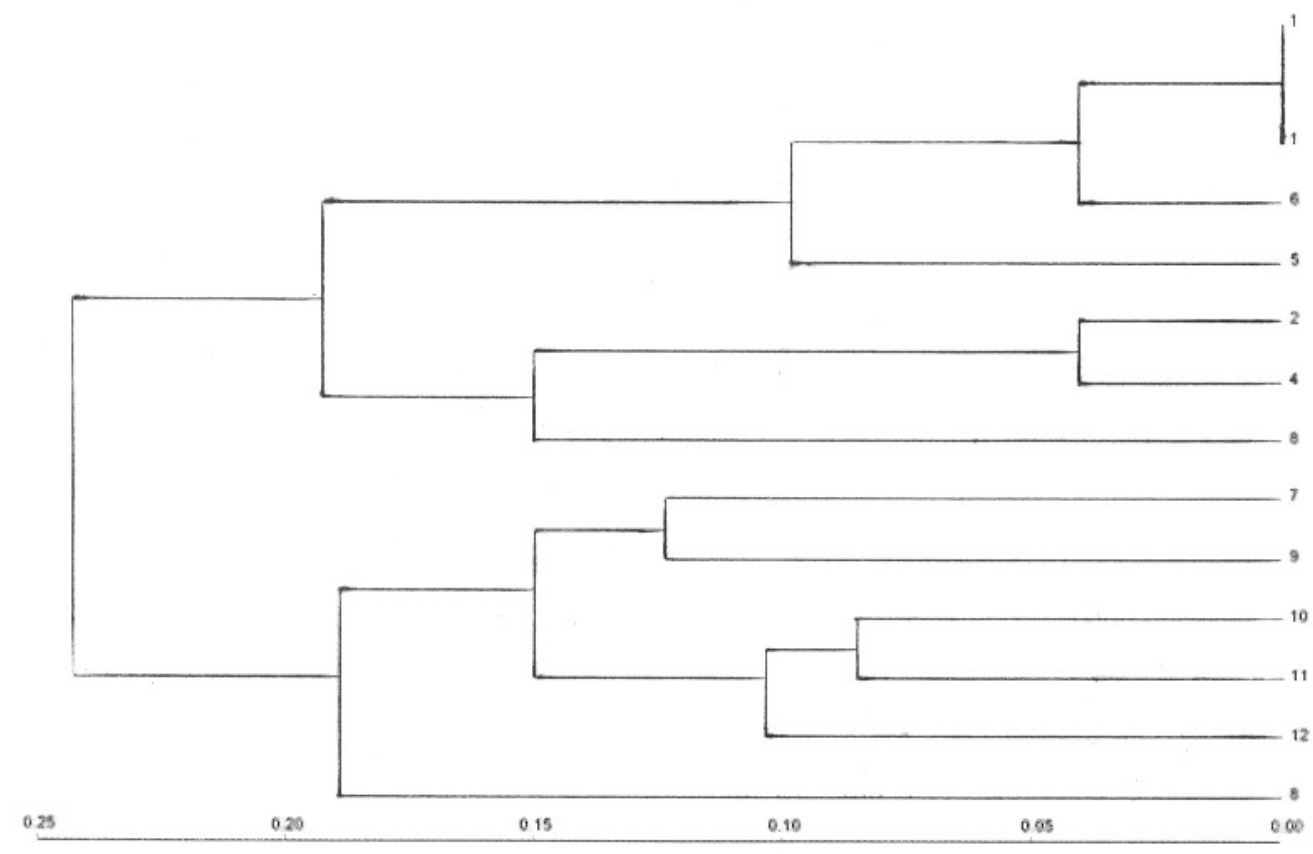

FIGURA 3. Dendrograma de distância genética de Nei (1972) a partir do método UPGMA, agrupando os diferentes materiais vegetativos estudados de E. najas. 


\section{AGRADECIMENTOS}

Os autores agradecem as instituições CESP, FAPESP e FUNDUNESP pelo apoio financeiro destinado a esta pesquisa, assim como aos engenheiros e funcionários da CESP pelo apoio nas atividades de campo.

\section{LITERATURA CITADA}

ALFENAS, A. C.; PETERS, I.; BRUNE, W. et al ; Eletroforese de proteínas e isoenzimas de fungos e essências florestais. Vicosa, 1991, $242 p$.

BALLVE, R. M. et al.; Isoenzimas na identificação precoce de híbridos nucelares no melhoramento de citros. Bragantia, Campinas, 50 (1):57 - 76, 1991.

CHELIAK, W. M.; PITEL, J. A.; Techniques for starch gel electrophoresis of enzimes from forest tree species. Patawawa National Foresty Institute, Canadian Foresty Service Information Report PI - X - 42, 1984. 49p.

GRATTAPAGLIA, D.; SEDEROFF, R. Genetic linkage maps of Eucalyptus grandis and Eucalyptus urophylla using a pseudotestcross: mapping strategy and RAPD markers. Genetics. v.137: 4, p.1121-1137, 1994.

HEDRICK, P. W.; A new approach to measuring genetic similarity. Evolution 25:276 - 280, 1971.

KISSMANN, K. G.; Plantas infestantes e nocivas Tomo I - Basf, 226 - 229, 1991.

LANGLINAIS, S. J. Evaluation of herbicides for control-of-aquatic weeds in Lake - Martin. Proceedings $27^{\text {th }}$ Annual Meeting Southern Weed Scienci Society, 288, 1974.
LESS, D. H.; Genetic diversity in the monoecious hydrophile ceratophyllum (Ceratophyllaceae). Am. - J. Bot. 78(8):1070 - 1082, 1991.

NEI, M.; Genetic distance between populations. Am. Nat. 106:283 - 292, 1972.

NEI, M.; Estimation of average heterozygosity and genetic distance from a small number of individuals. Genetics 89:583 - 589, 1978.

ROGERS, J. S.; Measures of genetic similarity and genetic distance. University Texas Publ., 7213:145 - 153, 1972.

ROHLF, F.J. NTSYS- pc: Numerical taxonomy and multivariate analysis system version 1.7. New York, Exeter Publ., 410p. 1992.

RYAN, F. J.; Partial characterization of a major family of proteins in turions of Hydrilla verticillata. Physiol. Plant. 73:486 - 493, 1988.

VERKLEIJ, J. A. C.; A comparative study of the morphology and isoenzyme patterns of Hydrilla verticillata ( L. f. ) Royle. Aquat. Bot., 17: 43 - 59, 1983.

WAIN, R. P.; HALLER, W. T. and MARTIN, D. F.; Isozyme in studies of aquatic plants. $\mathbf{J}$. Aquat. Plant Manag., 23:42 - 45, 1985.

WILLIANS,J.G.K.; KUBELIK, A.R.; LIVAK, K.; RAFAUSKI, J.A.; TINGEY, S.V. DNA polymorphisms amplifyied by arbitrary primers are usefull as genetic markers. Nucleic Acids Res., v.18, p.6531-6535, 1990.

YEH, F.C.; YANG, R.C.; BOYLE, T. Software Popgene (version 1.20) - Population Genetic Analysis. University of Alberta and Centre for International Forestry Research, July, 1997. 